\title{
The social potency of affect: Identification and power in the immanent structuring of practice
}

\begin{abstract}
We address the centrality of affect in structuring social practices, including those of organizing and managing. Social practices, it is argued, are contingent upon actors' affectively charged involvement in immanent, yet indeterminate social relations. An adequate understanding of this generative involvement requires a temporally-sensitive, critically-oriented theoretical framework, grounded in an affect-based ontology of practice. The relevance and credibility of this proposal is supported through an analysis of the interactions of Board members in a UK consulting company.
\end{abstract}

\section{Keywords}

Practice, affect, ontology

\section{Introduction}

The significance of affect, including emotion, is rarely registered or appreciated in accounts viewing the social world as comprising practices (e.g. Sandberg and Tsoukas, 2011). In empirical studies where practice is acknowledged to be affectively charged (e.g. Lok and de Rond 2013), the possibility that 'affect affects' practices is 'seen but unnoticed' (Garfinkel, 1967); it is pervasive, yet remains unthematised. In this paper, we seek to develop and demonstrate the critical and empirical implications of paying direct attention to affect in accounting for the social structuring of practice(s). We are especially interested in the unfolding relationship between affect and the 'basic grammar(s) within which possible objects are constituted', which 'mediates any kind of contact with reality' (Bhaskar and 
Laclau, 1998: 9). This grammar, which Laclau also terms 'discourse', is, they contend, 'largely unconscious...so the task of the discourse analyst is to explore the immanent grammars which underlie all kinds of meaningful intervention' (ibid).

Specifically, we will explore the affectively-driven operation of 'unconscious, immanent grammars', or discourses, enacted by directors of an IT consultancy, and so doing, seek to further the investigation of affect's mediating action on social reality. In addressing affect's significance in the (re)production of mundane work in this organization, we rely upon the 'Essex school' of discourse analysis initiated by Laclau (e.g. Laclau and Mouffe 1985). The Essex school is distinguishable from other schools of discourse analysis in its (postfoundationalist) conception of the 'structural undecidability' (Laclau 1995: 93) of the social. In this view, 'ontic' social relations and schemas which may appear superficially settled and permanent are actually constituted provisionally, and moment by moment, from their unfolding relationship with the 'ontological': an invisible but limitless 'open universe' of possibility comprised of Laclau's underlying, immanent grammars. A major research challenge associated with this approach is to recognise how this 'ontological' register may be significant in shaping the 'ontic' register - since the ontological is not directly available to the researcher in an empirical sense.

To address this challenge, our analysis makes use of a framework developed by students of Laclau: Glynos and Howarth's (2007, 2008) Logics of critical explanation (hereafter Logics) in which the 'ontic' and 'ontological' registers are juxtaposed dialectically (Laclau, 2000: 58). The framework facilitates consideration of what may be happening in each of these registers, and guides analysis of the possible socially generative relationship between the two: a relationship which animates Laclau's 'structural undecidability'. At the heart of the ontological-ontic dialectic is actors' ongoing affective identification with practices, and their associated behaviour in reproducing, defending, or challenging these, 
which constitutes this undecidable 'trace of contingency within the structure' (Laclau, 1993: 535). Drawing attention to this 'trace' of ontological contingency is an important analytical undertaking, since although the various manifestations of power within the ontic register are more or less identifiable to the researcher (Lukes, 1974), their ontological contingency remains unseen and unacknowledged; social configurations thus may appear more selfevident and stable than really they are.

An affect-based ontology of practice, guided by a Laclauian framework, exposes this underlying ontological contingency of power relations. The framework shows how social relations are immanently conditioned by actors' affective states and associated identifications and dis-identifications - and thus attends to the mutually constitutive, and analytically revealing, relationship between affect and power in organisational practice. Our study adds to a nascent body of work that has adopted Logics to inform empirical analysis (e.g. Wagenaar, 2011; West, 2011; Glynos, Klimecki and Willmott, 2012; Glynos, Speed and West, 2014).

In the following section of the paper, we locate our analysis within practice-based studies and research on affect. We then outline Glynos and Howarth's $(2007,2008)$ Logics approach in which an affective ontology is combined with an attentiveness to unfolding power relations in organisational practice. The framework incorporates psychoanalytic insights to highlight the potency of affectively-charged fantasies in the animation of social practices. In the third section, we analyse two episodes drawn from a study of Board interactions in an IT consulting firm, Associates.

We conclude that an affect-based ontology of practice holds a number of potentially radical implications for social/organizational theoretical development. Notably, it exposes shortcomings in established forms of analysis that operate solely on the ontic register - such as those that rely upon 'agency/structure' and/or 'micro/meso/macro' distinctions. To address 
these shortcomings, it proposes recasting such analyses within a more central, generative tension between ontic and ontological registers. Such a re-casting, we claim, will allow researchers to better attend to the incompleteness as well as the mutual constitution of 'structure' and 'agency', as well as to a 'politics of affect'.

\section{Locating and orienting our research}

The literature addressing aspects of affect is extensive, so we rely here upon a number of recent reviews, the most salient of which, for our purposes, are Brief and Weiss (2002), Fineman (1993), Elfenbein (2007), Schmidt and Gibson (2010), Simpson and Marshall (2010), and Voronov and Vince (2012). Their shared assessment is that, as a consequence of the dominance of variants of rationalism, affect has generally tended to be marginalized in social scientific analysis, including management and organization studies (for recent discussions, see Collins and Munro, 2010; Hynes, 2013). In this inauspicious context, the challenge is to appreciate how, as Barbalet (2001: 187, emphasis added) puts it, with regard to the study of emotion as a form of affect:

Emotion, as movement, is in that sense both external to the subject who experiences it and integral to their being as a consequence of their being moved by the feeling.

Emotion has a source outside of the self in its relations with others and is internally experienced as a function of active being. It is through the subject's active exchanges with others, through interaction, that emotional experience is both stimulated in the actor and orientating of their conduct.

We locate our study of affect within approaches that comprise the 'practice turn' (for reviews, see Corradi et al. (2008) and Nicolini (2012); see also Gherardi, 2009; Jansson, 2013; King, 2009; Lave and Wenger, 1991). We distinguish core contributions to the practice canon by reference to their central commitment: first, to a process-based ontology of 
continual 'becoming' (Thompson, 2011; Tsoukas and Chia, 2002); and second, to an epistemology that, by addressing the evolving accountability of practice (Rouse, 2001), attends to how behaviours, actions, and understandings of social acceptability (and thus contestability) are context-driven and become intelligible to selves and others 'in flight'. As noted by Wetherell and others (e.g. Stenner, 2009; Walkerdine, 2009), practice 'offers the best, bare bones, synthesising rubric for research on affect' (Wetherell 2012: 11), where 'analyses of affective practices...will take as their subject how these practices are situated and connected' (ibid.: 13). As we shall show, our intersubjective (rather than subjective) conception of affect is similarly intertwined and relational, and encourages a view of practice as a medium and outcome of relations of power. Within the practice canon, the focus of our study is upon an 'immanent logic of practice' (Chia and MacKay 2007: 219, italics omitted) whereby 'unconscious social forces shape and direct human intentions and actions' (ibid.: 232). This conception of practice owes much to the immanence of Heidegger's Dasein (which includes affective disposition as a core component) in its focus on how, unconsciously, 'cultural transmissions, socialization, institutionalization, disciplinary regimes, etc., play a crucial role in shaping an actor's modus operandi' (ibid.: 232, original italics). Narrowing our focus further still, we depart from Chia and Mackay (ibid.) in our interest in the 'psychosocial texture' (Wetherell 2012: 2) of this immanent logic, entailing a more encompassing conception of affect as 'a philosophy of force, becoming, potential, encounter and difference' that has 'influence, intensity and impact' (ibid.: 3), where affect is defined as 'embodied meaning-making' (ibid.: 4). Such a conception is distinguishable from 'psychological' approaches, which are typically more concerned with extracting affective states (specific moods and emotions) from their social context.

In studying the psychosocial texture of this immanent logic of practice, we locate our study within the NW quadrant of Sieben and Wettergren's (2010) 'compass' for 
understanding the landscape of affect studies. This quadrant combines the critical, postfunctionalist aim of politicising, rather then maintaining, existing relations, with a local/emergent approach that seeks to surface and illuminate dynamics of practice without being methodologically preoccupied with replicability or generalizability. The overriding concern of scholarship in this quadrant is with exploring the linkages between the "powerknowledge connection' and the 'embodiment' of emotion (Sieben 2007: 572).

\section{Logics as a conceptual framework}

\section{Social, political, and fantasmatic logics}

In addressing the tricky issue of researching and conveying others' affective states - a challenge which is perhaps most obvious in the study of 'atmospheres' (Anderson 2009) - in a way that is also attentive to the social situatedness of those states, we deploy Glynos and Howarth's (2008) Logics framework. Logics combines a focus on discourse, in the ontic register, with a Lacanian attentiveness to affective dynamics in the ontological register that is indebted to Lacanian psychoanalysis (Fotaki et al. 2012; see also Žǐzek, 1989; Laclau and Mouffe, 1985; Cederström and Spicer, 2013). Consistent with our affect-based ontology, Glynos and Howarth argue that the reproduction or transformation of social practices arises from the operation of three interweaving logics - social, political and fantasmatic - which govern the configuration of the socially generative relationships between discourse and affect.

Social logics rationalize and reproduce the status quo. Political logics, in contrast, operate to establish new practices as well as to transform practices in the face of the naturalizing effects of prevailing social logics. Most importantly for our analysis, fantasmatic logics provide the motivational force for social and political logics through affective identification with, and investment in, particular grammars/discourse. In supplying the 
psychosocial texture animating actors' affective motivations - either to reproduce (social logics) or to disrupt (political logics) the prevailing order - fantasmatic logics frame and mediate actors' identification, and resulting mode (or immanent logic) of engagement, with unfolding practice.

\section{Fantasmatic logics mediate actors' mode of engagement}

Unlike other framings of affective self-identification, such as those devised by Bourdieu (e.g. 1977) and Giddens (e.g. 1984), the Logics framework's affect-based ontology of practice (see Kemp, 2010; Thompson, 2012) accords central importance to the operation of this third, fantasmatic, logic. For researchers, this change in orientation means a shift from examining specific (ontic) 'practices' towards a focal attentiveness to actors' (ontological) mode of engagement: how actors reproduce or challenge social relations to the degree that they become affectively invested in, or distanced from, them (Glynos and Stavrakakis, 2008). In contrast, 'agency' and 'structure', which are the focal elements in contemporary social analysis, are considered to be secondary (ontic) configurations that emerge from this mode of engagement.

In theorising the mode of engagement, Glynos and Howarth (2007) adopt a Lacanian view of fantasmatic logics as deriving from libidinally felt motivation directed towards jouissance: a form of enjoyment-in-anticipation, the object of which can never be obtained: 'jouissance does not exist, it is impossible, but it produces a number of traumatic effects' (Žizek 1989: 164). These 'effects' manifest via fantasy: actors' subscription to identifications that 'paper over' the contingency of social life (Lok and Willmott, 2013), and distract/compensate for the (traumatic) unattainability of jouissance. In short, in accounting for the 'grip' of identity on the 'vector' of possible identifications (Glynos and Stavrakakis, 2008: 11; see also Glynos and Stavrakakis, 2008) fantasy mediates between affective motivation and socio-political reality, via the mode of engagement (Glynos and Stavrakakis, 
2008: 8; see also Frosh, 2002).

From a critical perspective, subjects' willingness to conform with ideologies and identities with which they are confronted depends on the extent to which jouissance associated with fantasies encourages them to disregard their underlying contingency/unattainability. To the extent that this occurs, 'domination...differs from [mere] authority and oppression in that agents are complicit in their acceptance of structures and practices that from the critic's point of view can be judged illegitimate or unjust' (Glynos 2010: 323) - leading potentially to self-exploitation (e.g. Costas and Fleming 2009).

\section{Using dimensions of the Logics to study psychosocial configurations}

Drawing together the discussion of Logics, the horizontal dimension in Figure 1 is concerned with how 'fantasmatic dynamics' mediate 'ethical and ideological forms of subjectivity' (Ekman 2013: 1161, original italics); and the vertical dimension addresses the social 'consequences' of this unfolding process (though they effectively comprise two dimensions of the same phenomenon). Taking each in turn, the horizontal ('naturalization') axis addresses the differential ways in which actors experience and address contingency: 'the ideological logic involves a subject struggling with competing hyper-intense fantasies, whereas the ethical logic involves a subject struggling with her or his tendency to fantasize at all' (Glynos, 2008: 291, in Ekman, ibid. 1165) because s/he recognises the underlying contingency/contestibility of these identifications, and thus resists 'buying in' to them.

\section{INSERT FIGURE 1 ABOUT HERE}

The vertical ('contestation') axis addresses the social 'consequences' of this process, in terms of maintaining and/or transforming social practices. At the 'social' pole, practices are reproduced with the minimum of contestation. At the 'political' pole however, practices are 
in the process of being instituted or challenged. As will become evident, the strongest affinities are between the ethical-political (disinvestment-challenge) poles, and also between the ideological-social (investment-acquiescence) poles. In particular, by underscoring the ontological contingency of local (ontic) practices that may otherwise appear ideologically self-evident or normative, the 'ethical' pole provides the conditions of possibility of critique. For the researcher, consideration of both psychoanalytical (naturalisation) and social (contestation) dimensions together affords analysis of psychosocial configurations, or articulations - and thus allows explicit analytical consideration of the affective component of social practice: of 'the closure of subjective identification' (Glynos and Howarth, 2007: 198). In so doing, such analysis affords (political) consideration of the affective vulnerabilities to which subjects expose themselves through their fantasmatic dynamics.

\section{Applying the logics}

Having the benefit of, but also departing from, previous attempts to operationalize the Logics framework (e.g. Clarke, 2011; Ekman, 2013; Holtzman, 2013), we now demonstrate its relevance for the empirical study of affect in the social structuring of practice. Consideration of the naturalization and contestation dimensions together can, we will suggest, illuminate the mediating operation of (affectively-felt) fantasmatic logics on both social logics (reproduction) and political logics (institution/transformation) (see Figure 2).

\section{INSERT FIGURE 2 ABOUT HERE}

Working round Figure 2, subjects' fantasmatic identifications can obscure the contingency of social life (left side of Figure 2); or, to the extent that people are less affectively invested in, and therefore less subject to these identifications, there is greater openness to, and awareness of, the underlying contingency/contestability of social relations 
(right side of Figure 2). In this regard, actors are either more favourably placed to act in ways that challenge those relations, or they are actively quiescent in their reproduction (they don't 'buy in', but they don't challenge, either). Conversely, to the extent that subjects are affectively invested in, and subject to, fantasmatic identifications, awareness of the contingency/contestability of normative relations of power is less likely, and so there is a greater propensity passively to reproduce those relations. Alternatively, actors may attempt to supplant established relations with another set of relations in which they are affectively invested.

Our analysis works outwards, identifying actors' (mediating) affective fantasmatic logics which we link to social and political logics along the two dimensions discussed above. Situated within our affect-based ontology of practice, the Logics framework facilitates analysis of how the conversations reported in fragments of our transcript presented below develop through several identifiable, if temporary, configurations of affectively-mediated logics.

\section{Research context}

Shared narratives at Associates: Will, Andy, and the researcher

The site of the research is a well-established mid-sized Metropolis-based consulting company which we call Associates (a pseudonym). At the time of the research, conducted in 2010, the company had been undergoing internal restructuring, as well as developing new propositions and capabilities in response to the post-2008 economic downturn. Will, Andy (the names are pseudonyms), and one of the authors (hereafter 'the Researcher') were all directors of the company, and had been attending Board meetings together since 2005. Notes were taken, by the researcher, on interactions between Will and Andy which occurred during three monthly Board meetings of during August-November 2010, of which two interactions are presented 
here. Due to the shared history between all three individuals, the unfolding meaning for the participants of the two episodes is only partially intelligible in the present tense as ' $[\mathrm{t}] \mathrm{ime}$ does not break for us into tiny segments. Our duration is a continuous gnawing of the past into the present where the present is infused with a burden of the past that does not pass, does not ever escape us' (Middleton and Brown 2005: 224).

The affective dynamics between Will, Andy and the Researcher (who has 20 years' immersion in Associates) are thus fundamentally relational, and historically-inflected. In Logics terms, all three were fantasmatically invested in the preservation of a strongly discernible self-identity that appeared partly defined, or reaffirmed, in their interactions with the others. As the empirical episodes show, the fantasmatic logics of the actors' respective self-investments mediated their mode of engagement with the social and political logics with which they confronted one other. Will and the Researcher had worked for the Company since its startup days. Andy, in contrast, had gained experience working in a larger consulting organization before joining Associates more recently. To provide additional details of Will and Andy's backgrounds is neither morally defensible nor practically relevant as this might allow their identification.

What, then, of how Will, Andy, and the Researcher conceived of themselves? Based on years of experience of interactions with Will and Andy, we believe that the following terms speak to Will's self-identity in the context of Associates: 'leader, 'considerate', 'straight talking', and 'people person'; those describing Andy's self-identity include 'leader' but also 'ambitious', 'corporate', and 'professional'; and those describing the Researcher's selfidentity include 'mediator', 'analytical', and 'reticent'. Taken together, Andy's selfidentifications might be collectively termed 'managerialist', Will's might be termed 'empathetic', and the Researcher's 'non-committal' in the sense that he often tried to avoid emotional subscription to either Will's or Andy's generally more dominant schemas (in 
Logics terms, it could be said that the Researcher tried semi-consciously to locate himself in the SE quadrant in Figure 2).

Further, all three displayed some awareness of the others' self-identifications, which appeared to have influenced the evolution of their own respective self-identities, as well as group identity over the years, in a way that is only historically, and relationally, intelligible. Within the context of Associates, the affective politics between Will, Andy, and the Researcher had been co-created, over time, in a manner that reflects a progressive 'intertwining of subjectivities' between ourselves and others as 'we observe their gestures, facial expressions, their rising and dampening of affect and then model, intuit and re-run their intentions and psychological states' (Wetherell 2012: 88). In our analysis, we will attempt to 'model, intuit and re-run' this fundamental affective relationality, describing a 'pairing of affective positions, normative turn and counter-turn, and processes of context-making for affective relational moves' (ibid.: 87).

\section{Interpreting shared narratives: Collection and analysis of data}

The method of data collection was covert (Goffman, 1968; Jorgensen, 1989) so as to minimise the researcher's influence on the 'natural' unfolding of the interactions. The ethics of such covert participant observation have been questioned but also selectively defended (eg. Herrera, 1999; Lugosi, 2006; Miller 2001), with some experienced ethnographers conceding that all fieldwork relationships invariably involve some covertness (e.g. Grills 1998). In the present study, the texts and supporting analysis were subsequently shared with relevant members of Associates, and consent to publication obtained. Despite this acceptance (or member 'validation'), our analysis doubtless harbours selective attentiveness to, and interpretation of, the episodes. Our narrative is necessarily a perspective-dependent version of 'the truth', but one whose frame of reference we have endeavoured to make explicit. 
If Adler and Adler's (1987) advice that data collection continues until one can 'act as a native', then saturation has resulted from the Researcher's extended period of immersion. Such immersion is especially valuable for analysis where close familiarity with subjects' emotional orientations is required. Specifically, and with regard to the approach advanced above and applied here, it is vital to have an in-depth and longitudinal appreciation of the affectivity of fantasmatic logics in relation to the social logics and political logics enacted in the research context. We readily acknowledge that the only empirical 'evidence' underpinning our attributions exists in the ontic, rather than ontological, register, which is never empirically 'available' in complete form; we have thus been careful to separate the two registers in our presentation of the data.

Our appeal to the value of 'immersion', the cri de coeur of all participant researchers, of course begs the question of any researcher's access to other peoples' emotions. To address this tricky issue, we refer to Sturdy's (2003) consideration of research on emotion where he contends that 'given some cultural understanding of the immediate social context, we can necessarily offer a valid or plausible interpretation of sentiments through observation'; and he further argues that 'immediate and biographical history...may provide insight into the emotional context and process' (2003: 86-7). An ability to 'read' and evaluate affect in the form of others' emotions is, on this interpretation, a basic social competency for organizational practice (as demonstrated in its breach), in which working familiarity with the discursive practice through which emotions are constituted is substituted for the more traditional concern with elusive 'inner feelings'.

This methodological approach resonates strongly with the view that:

The emotionality of narrative is more than the location of certain emotion words and phrases. It includes the relationship between the words, the metaphors used... and the sense of cadence, hesitation and silences detectable in the structure of the text or 
presentation (tape recording, video or observations). The researcher's challenge is sensitively to 'read' the emotional form and context of the text, while accentuating what is important for the particular inquiry. In doing so, the researcher is inevitably a part of the process, drawing upon emotion discourses 'in their head'. Such reflexivity is a feature of emotion knowing (Fineman, 2004: 733).

In this sense, what is attempted by the Researcher below is an abbreviated 'confessional tale' (Van Maanen 1988): a form of '[m]ethodological reflexivity, as expressed in confessional ethnography, [which] transforms the self by converting it to a new way of thinking and acting and writing - that way being the way of introspective reflection' (Webster 2008) that is sensitive to the 'relationships' to which Fineman (2004) refers.

\section{Empirical material}

Two episodes from the Board meetings are presented, and then analysed below. Each was selected for its relatively self-contained and accessible (e.g. jargon-free) nature, and both are sufficiently brief to allow their presentation within the space limitations of a journal article. Our intention in analysing the two episodes is to demonstrate the main theoretical proposition (affect-based ontology) by applying the Logics approach to analyse mundane episodes of organizational work. Such an aim is consistent with an acknowledgment that qualitative case studies 'typically ha[ve] more relevance to theoretical generalisation, which involves "suggesting new interpretations and concepts or re-examining earlier concepts or interpretations in new and innovative ways"' (Orum et al., 1991: 13). Our analysis of the episodes strives for 'naturalistic generalisability' (Stake 1978), at least insofar as its aspiration is to resonate with our readers' own sensemaking.

\section{Engaging with the empirical material}


Our analysis examines two exchanges between Will and Andy at which the Researcher was present, identified as Episodes 1 and 2 in two tables. The use of a tabular format more readily permits the exchanges to be read vertically, in 'pure' form as they occurred, as well as horizontally, in dialogue with our suggested configuration of Logics, whilst maintaining a clear separation between the two. The left hand column sets out the exchanges as they were recorded in the Researcher's field notes. The notes comprise the exchanges as they were spoken, and emotional cues that were observed [square brackets], together with observations about 'atmospheres' that were affectively experienced by the Researcher (round brackets). These observations take the form of single adjectives, in brackets in the left hand column of the Table for each episode, that describe how the room felt to the Researcher in a way that parallels others' descriptions of affective 'atmospheres' conceived inter alia as 'spatially discharged, quasi-objective feelings' (Böhme, 2006: 16), 'collective affects' (Anderson, 2009: 78), or contagious affect (Thrift, 2008). These observations may be casually termed 'subjective', but consistent with the conceptual framing of this paper, they are arguably intersubjective in their embodied sociality.

The right hand column locates our analysis within the Logics framework: it offers 'snapshots' of the different configurations of the three logics through which we argue that the dialogue passes as it unfolds. Finally, the analysis that follows each Episode has been written by the Researcher, and the narrative therefore moves into the first person where it has a more confessional style. This analytical approach, we suggest, offers a novel and promising, affect-attentive way to explicate the dynamics of everyday practices of organizing.

\section{INSERT EPISODE 1 HERE}




\section{Episode 1: Organizational Structure}

Applying the Logics framework, the above episode is seen to move through several psychosocial articulations. In the first, 'Regard of contingency: knowing challenge (invocation of political logic)', there is a configuration of political and ethical dimensions (recalling Figure 2) as Andy introduces the notion of stronger governance structures. This is an innovation that the Researcher believes Andy anticipates will be difficult, since it challenges the status quo (political logic) and invokes a long-standing difference, where Andy seeks more formality, and Will seeks informality. 'Company Handbook' is therefore a loaded phrase; its invocation creates a tension in the room that we all feel strongly. Such a tension is intelligible as an 'intention movement' (Stern 2004). Such movements are

not completed relational moves but mere beginnings of recognisable affective patterns. These seem like the moments preceding lightning strikes when sophisticated still photography shows threads of electrical connection beginning to manifest with the tallest objects in the field, before the strike completes the connection (Wetherell 2012: 87).

There is a tense feeling in the room, as Andy's introduction of the 'Company Handbook' [Andy 1] immediately invokes a historically-inflected, affective positioning: a specific configuration of power relations over which Andy has discursive mastery. Fantasmatically, my everyday, operational reading of Andy is that he is invested in a more corporate self-image in which 'moral' signifiers like governance structures make him feel confident/in control, whereas Will is invested in the reverse - and the apparent bipolarity of this dynamic may be exacerbated by my own (felt and perceived) passivity. In turn, it may be that I am invested fantasmatically in the notion of being a 'moderate' in relation to Will and Andy's 'excessive posturing'. For all three of us, these characterisations are historically- 
forged and long-acknowledged, and this tripartite 'shape' colours the way in which we are motivated to react, and experience. I suggest that our motivations in each case arise from our respective pursuit of jouissance, in which each of us wants to 'feel good': secure, and confident, about our positioning within this tripartite dynamic - when the opposite is normally the case. Re-visiting this sequence, and the 'tense' note in brackets, is to reconstitute a keen relationality: a viscerally-experienced patterning of mutual insecurity: of discursive move and counter-move in which I often occupied the position of despairing bystander.

In the second articulation, 'Regard of contingency: attempt to reproduce status quo (invocation of social logic)', a single sound [Will 1] from Will is sufficient to convey rich meaning to myself and Andy: his noncommittal 'Mmmmmm' response indicates that he is listening, that Andy may have a point (i.e. that Will's own position may be contingent) but does not agree anyway (attempt to reproduce status quo). Fantasmatically, Will appears emotionally invested in a 'straight-talking' and 'reasonable' self-image, which pits him against Andy's bid to position the Company Handbook as a self-evidently obvious improvement (in Will's view, such structures are poor substitutes for 'getting in a room and sorting things out face to face') - motivating him to invoke a social logic (reproduction of existing relations).

All three of us are highly sensitive to topics, such as this, that are emblematic of, and thus trigger, an historically-understood conflict: the psychodynamics of our interaction are always bound up with the 'tinderbox' of our mutual discursive patterning. In this articulation, Will's positioning combines social and ethical dimensions of the Logics, where he is 'ethically aware' of Andy's discursive move, but is reserving his position for now. Will's 'Mmmmmm' indicates that he is feeling frustrated at the direction this conversation may be 
about to take - at the likely effect that his 'regard of contingency' is likely to have on Andy in a moment's time - even as he utters the sound.

Sure enough, in the third articulation - Disregard of contingency: semi-conscious identification/challenge (defence of political logic) - Will's noncommittal response ignites feelings of frustration and hostility in Andy (and a similarly frustrated sense of 'been-herebefore' in myself - as indicated by the margin note 'aarrgghhhh'). Andy moves to a political/ideological configuration of dimensions, since fantasmatically his self-image seems bound up with his role as professional innovator, with experience of professional best practice, gained prior to joining Associates, that neither Will nor I possess (whilst allowing that this may be a partial reflection of a certain insecurity on my own part in this regard). In the terms used here, it appears to me strongly that the notion of being professionally 'in control' is a source of jouissance for Andy. Reflection on this encounter usually reconstitutes feelings of sympathy I felt at the time for Andy, because he often appeared less aware of these dynamics than Will - i.e. he seemed to operate more often than Will towards the 'ideological' pole of the 'naturalization' axis - with an attendant vulnerability when the contingency of schemas with which he identified came under challenge.

My reading of Andy's 'sigh', and related vocal tone in [Andy 2] is that he is aware of the significance of this particular skirmish both for his own self-esteem and for the deeply embedded power relations between him and Will (i.e. there is an air of resignation to some inevitability about their interaction). Recalling that Andy has mastery of this particular 'grammar', discursive closure around the signifiers of 'good governance' represented by the Handbook offers him the prospect of ontological security. However, the frustrated demeanour may betray an awareness that satisfaction of this 'lack' in the form of 'ontic closure' - turning this contingency into local reality - is contingent upon Will's ethical value- 
choice, as well as his own - in a manner recalling Žizek’s comment, earlier, about the trauma associated with the unachievability of jouissance.

Will's response in the fourth articulation - Disregard of contingency: semi-conscious identification/challenge (defence of social logic) - appears to reinforce the precariousness of Andy's position. Will responds [Will 2] to Andy's sigh with a strained, terse tone of voice (both seem to strive to maintain neutral body language), betraying some semi-conscious awareness that there is more at stake than the subject of this particular exchange - an awareness which mirrors that of Andy, and certainly my own (indeed, the three are relationally constituted). Will now justifies his position and makes clear why he disagrees with Andy ('ideological' and 'political' dimensions), as he shores up his persona as a 'people person'. He appeals to an alternative discursive grammar: 'that magic' (Associate's traditionally friendly culture), and thus the self-evidence of not 'throw(ing) the baby out with the bathwater'. As an observer who shares Will and Andy's historically-established affective patterning and 'embodied meaning-making' (Wetherell, ibid.) is evident to me from the simmering atmosphere in the room that this skirmish has become much more about Will and Andy's 'empathetic' vs 'managerialist' positioning, than any comparatively innocuous debate regarding the relative efficacy of a Corporate Handbook.

Finally, by the fifth articulation - Regard of contingency: knowing challenge (defence of political logic) - the studiedly neutral body language maintained thus far by both Will and Andy slips as the (affective) atmosphere in the room becomes openly hostile, and Andy, visibly exasperated, knocks back Will's challenge [Andy 3], before tailing off with a theatrical sigh of frustration. As my notes record, the room feels 'unfriendly' - a relationally affective dynamic - as we appeared locked into (yet another) stalemate, and I felt like leaving. It seems to me that Andy is representing his challenge to the status quo as no more than (self evident) 'best practice': a 'discursive grammar' that denies its own contingency, 
whilst knowingly challenging Will's assertion that he is proposing to swamp people with rulebooks.

\section{INSERT EPISODE 2 HERE}

\section{Episode 2: More sharing of client contacts}

Applying the Logics framework this time to Episode 2, in the first articulation - Disregard of contingency: semi-conscious identification/challenge (invocation of political logic) - the psychodynamics of Andy and Will's interaction appear conditioned once again by their mutual fantasmatic investment in the 'tinderbox' of a relationally-felt rivalry. Such rivalry manifested, as usual, in a destructive compulsion towards conflict, as each pursued jouissance in the form of the unattainable ontological security of mastery over the other. In this exchange, Andy challenges how contacts are normally used [Andy 4] - that is, in ways that are sub-optimal from his standpoint - and conjures up a fantasy of the dire consequences of maintaining the status quo, presented as normative outcome ('political' and 'ideological' dimensions of the Logics). He appears genuinely to believe that Associate's use of contacts is sub-optimal (disregard of contingency) - rather than just one of several, equally contingent, value choices. In terms of my own affective involvement, my 'been-here-before/expectant' notes indicate a sense of expectancy of re-opening old wounds. This 're-opening' occurred frequently during meetings between the three of us. Revisiting the empirical material, it is inconceivable to me that this affective sense was not shared by all of us, because its shared nature was what lent it its intensity.

In the terms advanced here, Andy appears to be unaware of what I read, via the Logics, as his own fantasmatic investment in the pursuit of jouissance, or ontological security, that underlies his proposal of 'leveraging our contacts better'; Andy would frequently make 
suggestions, such as this, based in a 'managerial' approach to administrative control through which, as previously noted, he appeared to gain in confidence and a sense of ascendancy. However, if Andy is relatively unaware of the ontological contingency of the ontic schema he is advancing, I am confident that he is semi-aware that this subject touches on the historical, discursive web of relations that has built up between him and Will in which they/we are both/all emotionally invested, and that as a result, his suggestion is unlikely to go uncontested (political logic).

In the second articulation - Disregard of contingency: semi-conscious identification/challenge (invocation of social logic) - Will appears to sense an attempt in the previous articulation by Andy [Andy 4] to normalise social relations around some kind of structured communication regime ('leveraging our contacts across the company') over which Andy will have control. With a grim relish, Will now appears [Will 3] to 'toy' with Andy. This is apparent from his 'mischievous' tone of voice, together with his assessment that, in making his ostensibly innocuous suggestion, Andy is proposing that 'people are just going to give up their client relationships'. This is exactly the sort of escalatory behaviour that I would occasionally tell Will or Andy was 'a bit unnecessary' (usually on a one to one basis, often after a disagreement between them).

Although Will probably believes in his own discursively stated position (disregard of contingency), my reading is that Will's response is motivated as much by self-image as by any vigorous opposition to 'leveraging contacts' per se. Within the framework advanced here, Will is motivated in this exchange by the need to 'paper over the cracks' of his own ontological contingency and construct/reinforce his own self-image ontically (in this instance) as a 'people person' by 'explaining' to Andy how people are likely to behave 'in reality' (based, perhaps, on his own superior empathy: semi-conscious identification) - and casting Andy in an opposing, emotionally unintelligent, role. Fantasmatic motivation 
towards self-realisation as a 'people person' appears to inflect Will's readiness to quickly broaden the debate, which escalates rapidly from Andy's suggestion about 'working together', to a barely disguised claim about relative empathy. Such motivation - jouissance is apparent to me because there appears to be more going on than a simple discursive argument - for which Will's pursuit of a secure self-image is the most intuitive explanation.

In response, Andy's 'dogged' advancement of the need for 'more robust pipeline management' [Andy 5] in the third articulation - Disregard of contingency: semi-conscious identification/challenge (defence of political logic) - appears to me akin to a fantasmatic 'battening down of hatches' in response to what Andy will, in my view, inevitably interpret as Will's [Will 3] implied identification of him as a bloodless managerialist whom people will not obey simply 'because they've been told to' (i.e. by Andy). Once again, Andy's strategy is to invoke ideologically normative 'best practice' (see previous excerpt) in the form of the 'pipeline', etc. ('ideological' and 'social' dimensions). Visible in Andy's dogged adherence to the 'grammar' of his more structured approach to organizational management, and associated ascendancy, is once again a strength of emotion that transcends the mere (cognitive) articulation of a minor difference in position. As a regular participant in such exchanges, it seems to me that neither Andy or Will is fully affectively emancipated from their respective discursive identifications: in the terms advanced here, their affectively-driven needs for fantasmatic identification leads each to disregard the contingency inherent in their respective positions. It is my feeling that such exchanges contain an insecure, and perhaps distinctively masculine, posturing element that is 'all about them', and not necessarily about Associates, that triggers my own feelings of 'hardening cynicism'.

The final articulation - Regard of contingency: knowing challenge (defence of social logic)- implies that the hardening cynicism I feel is shared (co-created?) with at least Will. This is my intuitive reading of the situation, because Will responds with a flat rebuttal. In our 
analysis, the rebuttal is fantasmatically driven, because it is underpinned with the logic of his self-identification as 'straight talking' and 'reasonable' (he can 'just tell it like it is, based on his insights as a 'people person'). The outcome is an underlining of what, from Will's point of view, is the contingency of Andy's assertion of self-evidence ('ethical' and 'political' dimensions). Temporary 'ontic closure' is achieved, with the preservation of the social logic of status quo - but at the expense of cordiality. The existing political settlement has been reproduced - for now.

What of my own fantasmatic identification? Building on the confessional observations thus far, and attempting an ethical reflexivity in the SE quadrant of Figure 2, it seems to me that my own jouissance is bound up in some way with my ability to work within Associates and yet maintain my own independence: to be 'in it but not of it'. Whilst such a 'squaring of the circle' is clearly as impossible for me as discursive mastery of the Other is for Will and Andy, I sense that it forms an ulterior source of motivation that pre-positions me no less than theirs: in this sense, I am no more 'in control' during these exchanges than they are.

\section{Discussion}

Shifting analytical focus from 'ontic' to 'ontological' in practice studies

In analyses of practice, the significance of affect, in the form of emotions, feelings and moods, tends to be backgrounded. Even those who have acknowledged the orienting role of affect in providing practice with a 'sense of direction' (Shotter, 2011: 6) rarely analyse practice from within an affectively-informed, critical ontology (see Clough, 2007). To counteract this relative neglect, we have shown the relevance of employing an affect-based ontology of practice in illuminating relational, emergent everyday 'organizing' (Czarniawska, 2008). Affect, we have suggested, is of central importance for understanding the animation and reproduction of practice - as illustrated by the detailed analysis of the episodes at 
Associates in which we have shown how affect-saturated identifications and transient social 'settlements' are accomplished within evolving, politically charged, social relations with social, political, ideological, and ethical dimensions along axes of naturalization and contestation.

For the directors at Associates, moment-by-moment articulation of their world of mutual intelligibility involves (re)production of meaningful, but precarious, 'settlements' between these dimensions: in endorsements, 'gentle testing/questioning', outright challenges, ironic compliance with social structures, and so on. For researchers, understanding why such settlements occur, and are supplanted with others, requires engagement with an impelling dynamic between ostensibly firm ontic 'structures' and ontologically fluid, affectively charged 'processes' upon which the seeming firmness of the ontic register is contingent at all times: unfolding 'practice' comprises the generative tension between ontic and ontological registers. This dynamic arises from the irreducibility of the ontological to the ontic register, or as Laclau (2000: 81) puts it, 'there is no logical transition from an unavoidable ethical [ontological] moment...to any particular [ontic] normative order. There is an ethical investment in particular normative orders, but no normative order which is, in and of itself, ethical'.

In consequence, a particular issue for future consideration is our proposal of a fundamental shift in analytical focus within practice studies: from studying phenomena of the ontic register, to studying subjects' mode of engagement within the ontological register, before 'working outwards' to consider its ontic consequences. It is actors' mode of engagement with unfolding practices, rather than unfolding practices themselves, that constitutes the locus of social reproduction and/or transformation. With this shift comes a particular ethnographic challenge that is perhaps less common within practice studies that are principally concerned with the 'ontic': addressing the (ontological) intentions and 
psychological states of others (recalling Wetherell, ibid.). Given the relational constitution of affect, researchers are likely to have to provide more confessional accounts of their own affective intertwining with their research subjects: deploying an affect-based ontology to study social practices invites the incorporation of researchers' own emotions, feelings and moods into the study of organizing; research may need to become more longitudinal as a result. We suggest that our own, initial attempt to deploy an affect-based ontology to venture 'ontological explanations for ontic phenomena' is at best incomplete; and so, it may usefully stimulate the generation of better, more mature conceptual frameworks within which to study subjects' modes of engagement.

\section{Towards a politics of affect}

Unpacking social practices requires a critical engagement with the visceral operation of power within organisations, including actors' own complicity in reproducing the relations through which they are dominated and oppressed - a characteristic that we foregrounded in our analysis of Associates. A particular feature of an affect-based ontology, visible throughout the paper, is a foregrounding of the way in which actors' historical immersion in power relations conditions their self-identifications. Within the psychoanalytically-informed analysis advanced here, such immersion combines with actors' pursuit of an ultimately unattainable jouissance to offer a (for them) compelling, often destructive motivation for behaving in the way that they do. Thus for Will, fantasmatic pursuit of jouissance, or ontological security, entailed fantasmatic subscription to an identity as a 'people-person'; for Andy, it was pursuit of peer recognition as a 'professional'; for the Researcher, it was an ability to remain 'semi-detached' from (better than?) the posturing at Associates.

Since identification constitutes a form of domination to the extent that actors are affectively complicit in their own acquiescence, actors' increased awareness of their selfidentifications with social structures and practices may thus hold emancipatory potential (Lok 
and Willmott, 2013) - as well as offering some insulation from Žĭzek's 'traumatic effects' when fantasy is ultimately unrealised. Bringing these observations together, we suggest that an analytical attentiveness to a 'politics of affect' - the mutually constitutive and analytically revealing relationship between affect and power in organising - may be a necessary corollary for an affective ontology of practice.

Researchers seeking to study the politics of affect can call upon two particular strengths of the Logics framework as demonstrated here. First, we have addressed the emergent, generative dialogue between ontological and ontic registers of unfolding practice - affording what we contend is a more rounded account of social reality informed by both registers. In placing 'contingency within the structure' at the centre of such analysis, the precariousness (and thus 'political' contestability) of practices that we routinely reproduce, modify or transform, and take to be normal, is underlined. Second, our analysis has incorporated a motivational explanation for affective politics: the central role of fantasy offers a plausible account for the differential extents to which, as actors, we are dis/inclined to recognise the radical contingency (broader ontological instability) of ontic practices and choices in which we are implicated.

For example, in their sedimentation of social reality, Will and Andy are seen to engage in fantasmatic appeals: to the self-evident good of 'robust structures'; to the obvious good sense of not 'swamping people with rulebooks' (Andy 2; Will 2); to the clear need to 'leverage our contacts across the company'; and to 'a robust pipeline management approach' (Andy 4; Andy 5). These appeals, we have suggested, are made in the pursuit of political logics (proposals for change) as well as social logics (maintenance of the status quo). Such practices arise from affectively-driven identifications, derived from available moral grammars. Ontically, the outcomes-in-process of Will and Andy's interactions are the result of how each rallies ontologically around the ideological 'standards' with which he identifies. 
For example, it might have been comparatively easy for Will to endorse - passively or actively - Andy's appeals to 'robust structures', 'leveraged contacts', and 'pipeline management'. Will would then be complicit in concealing the radical contingency of these ideas (bottom left quadrant of 3), were it not for his ongoing affective commitment to constituting his self-identity as 'straight talking' and a 'people person' - a commitment which results in him challenging the givenness of Andy's standards. It is arguable that a greater self-awareness of their mutual processes of subjection might have enabled both Will and Andy to reach a more empathetic accommodation - an insight of some practical potential in engendering greater mutual awareness between organisational actors.

\section{Conclusion}

In applying Logics to analyse empirical material, our study has contributed to remedying the 'poststructuralist methodological deficit' identified by Zienkowski (2012: 504): that is, a comparative lack of methodologies for studying relationally-conceived phenomena. More specifically, we have sought to develop and apply a methodology for examining the centrality of affect in the animation of practice, with the anticipation that future studies will engage with it and build upon it. Through our empirical analysis, we proposed and applied a method for presenting and analysing detailed ethnographic material within a psychosocial, immanent logic of practice. Investigating affective contingency within the structure entails an analytical distinction between ontic 'structures' and ontological affective 'processes' upon which such structures remain contingent at all times. Specifically, we presented Episodes One and Two of the Associates data in tabular format that presents empirical material ('Text') in the ontic register alongside an interpretation of the 'Configuration of social, political, and fantasmatic Logics'). We then offered a 'confessional' explanation of the underlying dynamics of unfolding practice in the ontological register. We believe this to be a productive way of 
displaying and unpacking the ontic/ontological dialectic within the Logics, but further exploration of these issues could usefully be undertaken in future research. Particular limitations of our research involve the inductive inference of ontological phenomena from ontic data; although we hope to have offered an open, and plausible, account of our analysis within a structured framework, we hope that others may seek to improve on our preliminary attempt.

Our affect-based ontology of practice, and associated methodology, led us to two significant observations which, we suggest, merit further consideration within the practicebased research community. First, practice-based research which is presently hinged around study of the structure/agency relationship should instead be embedded in, and oriented by, the generative dynamic between the ontic and the ontological, as addressed here. Whilst we have endeavoured to unpack some of the more immediate implications of such a shift, we expect that this may be only the beginning. Second, an affectively-located analysis of motivation invites a particularly nuanced appreciation of the operation of power within organisational practice, in which ethical actors may be both protagonists as well as complicit subjects. Such an appreciation offers an opportunity to deepen existing theories of self-regulation, such as governmentality (e.g. Foucault 2010) to incorporate an unfolding sensory apprehension of, and identification with, the social, with implications for critical management studies and beyond. 


\section{BIBLIOGRAPHY}

Adler P and Adler P (1999) The ethnographers' ball - revisited. Journal of Contemporary Ethnography 28(5): 442-450.

Anderson B (2009) Affective atmospheres. Emotion, Space and Society 2(2): 77-81.

Barbalet J (2001) Emotion, Social Theory and Social Structure: A Macrosociological Approach. Cambridge: Cambridge University Press.

Bhaskar, R and Laclau E (1998) Discourse Theory vs. Critical Realism. Alethia 1(1): 9-14. Bourdieu P (1977) Outline of a Theory of Practice. Cambridge: Cambridge University Press. Brief A and Weiss H (2002) Organizational Behavior: Affect in the Workplace. Annual Review of Psychology 53(1): 279-307.

Cederström K and Spicer A (2014) Discourse of the real kind: A post-foundational approach to organizational discourse analysis, Organization 21(2): 178-205.

Chia P and Mackay B (2007) Post-processual challenges for the emerging strategy-aspractice perspective: Discovering strategy in the logic of practice. Human Relations 60(1): $217-242$.

Clarke M (2011) Talkin' 'bout a revolution: the social, political, and fantasmatic logics of education policy. Journal of Education Policy 27(2): 173-191.

Clough P (2007) (ed) The Affective Turn: Theorizing the Social. Durham: Duke University Press.

Corradi G, Gherardi S and Verzelloni L (2010) Ten good reasons for assuming a 'practice lens' in organization studies. Management Learning 41(3): 265-283.

Costas J and Fleming P (2009) Beyond dis-identification: A discursive approach to selfalienation in contemporary organizations. Human Relations 62(3): 353-378. 
Czarniawska B (2008) A Theory of Organizing. Cheltenham: Edward Elgar.

Ekman, S. (2003) Fantasies about work as limitless potential - how managers and employees seduce each other through dynamics of mutual recognition. Human Relations 66(9): 11591181.

Elfenbein H (2007) Emotion in Organizations: A review in stages. Institute for Research on Labor and Employment, UC Berkeley Working Paper 01-19-2007.

Fineman S (1993) Emotion in Organizations. Thousand Oaks, CA: Sage.

Fineman S (2004) Getting the measure of emotion - and the cautionary tale of emotional intelligence' Human Relations 57(6): 719-740.

Fotaki M, Long S, and Schwartz H (2012) What can psychoanalysis offer organization studies today? Taking stock of current developments and thinking about future directions, Organization Studies 33(9): 1105-1120.

Foucault, M (2010) The Government of Self and Others: Lectures at the Collège de France 1982-1983, Davidson AI, (ed), translated by Burchell, G. New York: Palgrave Macmillan. Frosh S (2002) Key concepts in Psychoanalysis. London: The British Library. New York: New York University Press.

Garfinkel, H (1967) Studies in Ethnomethodology. Englewood Cliffs, NJ: Prentice-Hall.

Gherardi, S (2009) Introduction: the critical power of the practice lens, Management learning, 40(2): 115-128.

Giddens A (1984) The Constitution of Society: Outline of the Theory of Structuration. Oxford: Polity Press.

Glynos J (2003) Self-Transgression and freedom. Critical Review of International Social and Political Philosophy 6(2): 1-20. 
Glynos J and Howarth D (2007) Logics of Critical Explanation in Social and Political Theory. London and New York: Routledge.

Glynos J and Howarth D (2008) Critical Explanation in Social Science: A Logics Approach. Swiss Journal of Sociology 34(1): 5-35.

Glynos J and Stavrakakis Y (2008) Lacan and political subjectivity: fantasy and enjoyment in psychoanalysis and political theory. Subjectivity 24(1): 256-274.

Glynos J, Howarth D, Norval, A, and Speed, E (2009) Discourse Analysis: Varieties and Methods. ESRC National Centre for Research Methods Review paper NCRM/014, National Centre for Research Methods.

Glynos J (2010) Power, discourse, and policy: articulating a hegemony approach to critical policy studies. Critical Policy Studies 3(3): 309-335.

Goffman E (1968) Stigma. London: Penguin.

Grills S (ed) (1998) Doing ethnographic research: Fieldwork settings. Thousand Oaks: Sage. Herrera C (1999) Two arguments for 'covert methods' in social research. British Journal of Sociology 5(2): 331-343.

Howarth D (2012) Power, discourse, and policy: articulating a hegemony approach to critical policy studies. Critical Policy Studies 3(3-4): 309-335.

Howarth D (2013) Poststructuralism and after: Structure, subjectivity and power. London: Palgrave Macmillan.

Jansson N (2013) Organizational change as practice: a critical analysis. Organizational Change Management 26(6): 1003-1019.

Jorgensen D (1989) Participant Observation: A methodology for human sciences. Newbury Park: Sage. 
Kemp C (2010) Building Bridges between Structure and Agency: Exploring the Theoretical Potential for a Synthesis between Habitus and Reflexivity. Essex Graduate Journal of Sociology 10: 4-12.

King D (2009) Journeys into critical thinking; intersecting Foucault into the organizational practice debate, Critical Management Studies at Work, Wolfram Cox J, LeTrent-Jones T, Voronov M and Weir D (eds), Edward Elgar, Cheltenham, p130-143.

Knights D and Willmott H (1989) Power and subjectivity at work: From degradation to subjugation in social relations. Sociology 23(4): 535-558.

Laclau, Ernesto (1993) Discourse, A companion to contemporary political philosophy, Goodin, RE. and Pettit, P (eds), Oxford: Blackwell, 431-437.

Laclau, E 1995 The Time is out of Joint. Diacritics, 25(2): 86-96.

Laclau E and Mouffe C (1985) Hegemony and socialist strategy: Towards a radical democratic politics. London: Verso.

Lave J and Wenger E (1991) Situated Learning: Legitimate Peripheral Participation. Cambridge: Cambridge University Press.

Lok J and de Rond M (2013) On the plasticity of institutions: Containing and restoring practice breakdowns and the Cambridge University boat club. Academy of Management Journal 56(1): 185-207.

Lugosi P (2006) Between Overt and Covert Research: Concealment and Disclosure in an Ethnographic Study of Commercial Hospitality. Qualitative Inquiry 12(3): 541-561.

Middleton D and Brown SD (2005) The Social Psychology of Experience: Studies in Remembering and Forgetting. London: Sage. 
Miller JM (2001) Covert participant observation: Reconsidering the least used method. In Miller JM and Tewksbury R (eds) Extreme methods: Innovative approaches to social science research. Boston: Allyn \& Bacon, pp.13-21.

Nicolini D (2012) Practice theory, work, and organization, Oxford, Oxford University Press. Orum AM, Feagin JR and Sjoberg G (1991) The nature of the case study. In Feagin JR, Orum AM and Sjoberg G (eds) A Case for the Case Study. Chapel Hill: University of North Carolina Press.

Rouse J (2001) Two concepts of practices. In Schatzki TR, Knorr-Cetina K and von Savigny E (ed.) The Practice Turn in Contemporary Theory. Routledge, London, pp. 189-98.

Sandberg J and Tsoukas H (2011) Grasping the logic of practice: Theorising through practical rationality. Academy of Management Review 36 (2): 338-360.

Schmidt D and Gibson D (2010) Emotions in Ethics and the Workplace: How can Feelings Be Integrated into Business Pedagogy?' $13^{\text {th }}$ Annual Colleagues in Jesuit Business Education (CJBE) Conference, Marquette University, Milwaukee, Wisconsin.

Shotter J (2011) Reflections on sociomateriality and dialogicality in organization studies: from 'inter-' to 'intra-thinking'... in peforming practices. Paper for submission to the book series Perspectives on Process Organization Studies (P-PROS), Volume 3, Proceedings of the Third International Symposium on Process Organization Studies in Corfu, June 16-18.

Sieben B (2007) Doing research on emotion and virtual work: A compass to assist orientation. Human Relations 60: 561-580.

Sieben, B. and Wettergren, A. (2010) Emotionalizing Organizations and Organizing Emotions. New York: Palgrave. Macmillan. 
Simpson B and Marshall N (2010) The mutuality of emotions and learning in organizations. Journal of Management Inquiry 19(4): 351-365.

Stake RE (1978) The case study method in social inquiry. Educational Researcher 7: 5-8.

Sturdy A (2003) Knowing the unknowable? A discussion of methodological and theoretical issues in emotion research and organization studies. Organization 10(1): 81-105.

Thompson M (2011) Ontological shift or ontological drift? Reality claims, epistemological frameworks and theory generation in organization studies. Academy of Management Review, 36(4): 754-773.

Thompson M (2012) People, practice, and technology: restoring Giddens' broader philosophy to the study of information systems. Information and Organization, 22(3): 188-207.

Thrift N (2008) Non-Representational Theory: Space, Politics, Affect. Abingdon: Routledge.

Tsoukas H and Chia R (2002) On organization becoming: rethinking organizational change. Organization Science 13(5): 567-582.

Van Maanen J (1988) Tales of the Field: On Writing Ethnography. Chicago, Chicago UP. Wagenaar H (2011) Meaning in action. Intepretation and dialogue in policy analysis. New York: M.E. Sharpe.

Webster J (2008) Establishing the 'Truth' of the Matter: Confessional Reflexivity as Introspection and Avowal. Psychology \& Society 1(1): 65-76.

West K (2011) Articulating discursive and materialist conceptions of practice in the logics approach to critical policy analysis. Critical Policy Studies 5(4): 414-433.

Wetherell M (2012) Affect and Emotion. London: Sage. 
Willmott HC (1986) Unconscious Sources of Motivation in the Theory of the Subject; An Exploration and Critique of Giddens' Dualistic Models of Action and Personality. Journal for the Theory of Social Behaviour 16(1): 105-122.

Zienkowski J (2012) Overcoming the post-structuralist methodological deficit metapragmatic markers and interpretive logics in a critique of the Bologna process.

Pragmatics 22(3): 501-534.

Žǐzek S (1989) The sublime object of ideology. London: Verso. 
ANALYSIS

Episode 1: Organizational structure

\begin{tabular}{|c|c|}
\hline Text & $\begin{array}{l}\text { Configuration of Social, } \\
\text { Political and } \\
\text { Fantasmatic Logics (cf. } \\
\text { Fig 2) }\end{array}$ \\
\hline $\begin{array}{l}\text { Andy (1): OK, moving onto the Company Handbook. } \\
\text { (Tense) }\end{array}$ & $\bullet$ \\
\hline Will (1) [noncommittally]: Mmmmmm. & \\
\hline $\begin{array}{l}\text { Andy (2): [Sigh] We just don't seem to take these things } \\
\text { seriously here. There's no way we're going to be able to get } \\
\text { growth by competing with the likes of xxx and xxx unless we } \\
\text { get some more robust structures in place. And this includes } \\
\text { more operational delivery management, more detailed } \\
\text { internal reporting procedures and business planning at } \\
\text { manager level, and a company code of practice. We're just } \\
\text { going to come unstuck otherwise - you'll see. } \\
\text { (aarrgghhhh) }\end{array}$ & $\bullet$ \\
\hline $\begin{array}{l}\text { Will (2) [tersely]: I'm sorry but you know the way I feel } \\
\text { about this. We already have perfectly good processes in } \\
\text { place; we all want to carry on growing but there's no way } \\
\text { we're going to throw the baby out with the bathwater. We're } \\
\text { not... Xxx, and we're just going to lose that magic if we } \\
\text { swamp people with rulebooks. }\end{array}$ & $\bullet$ \\
\hline $\begin{array}{l}\text { Andy (3): [Visibly frustrated] Clearly, I'm not proposing } \\
\text { swamping anyone with rulebooks, Andy, it's just basic good } \\
\text { practice. I really...[sigh]. } \\
\text { (unfriendly, want to leave) }\end{array}$ & $s$ \\
\hline $\mathrm{E}$ & \\
\hline
\end{tabular}

Episode 2: More sharing of client contacts 


\begin{tabular}{|l|l|}
\hline & $\begin{array}{l}\text { Political } \\
\text { Fantasmatic Logics (cf. } \\
\text { Fig 2) }\end{array}$ \\
\hline Andy (4): We really need to think of a way of leveraging our \\
At the ABC supplier briefing, it was obvious that xxx and yyy \\
had already spoken to the people in the business - and I know \\
for a fact that Jill knows some of those people - I felt really \\
foolish. Things are tightening up, and going forwards our \\
ability to form and draw on these relationships will be make or \\
break. \\
(Been-here-before/expectant)
\end{tabular}




\section{Political dimension}

"subjects articulate their feelings of dislocation by reactivating the contingent foundations of - and challenging - existing social relations in the name of a principle or ideal"

Ideological dimension

"subjects are complicit in concealing the radical contingency of social relations"

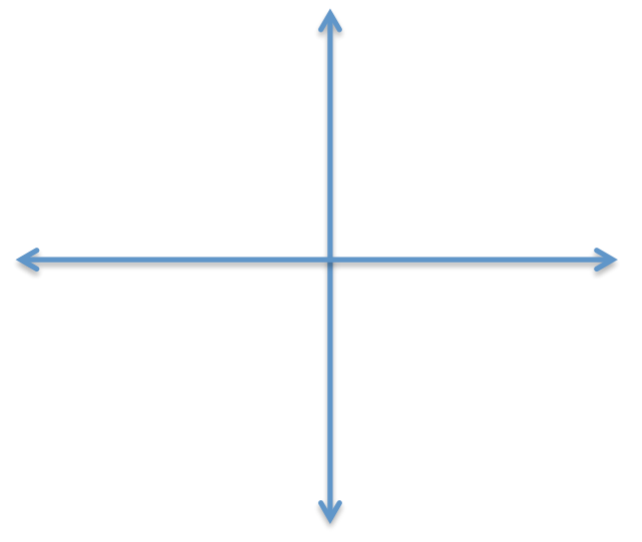

Social dimension

"subjects are absorbed in their practices...the radical contingency of social relations has not been registered in the mode of public contestation"
Ethical dimension

"subjects engage in their practices in a way that is attentive to the radical contingency of social relations"

Figure 1: Four dimensions of social relations (Glynos and Howarth 2007:112), modified to include original explanatory text

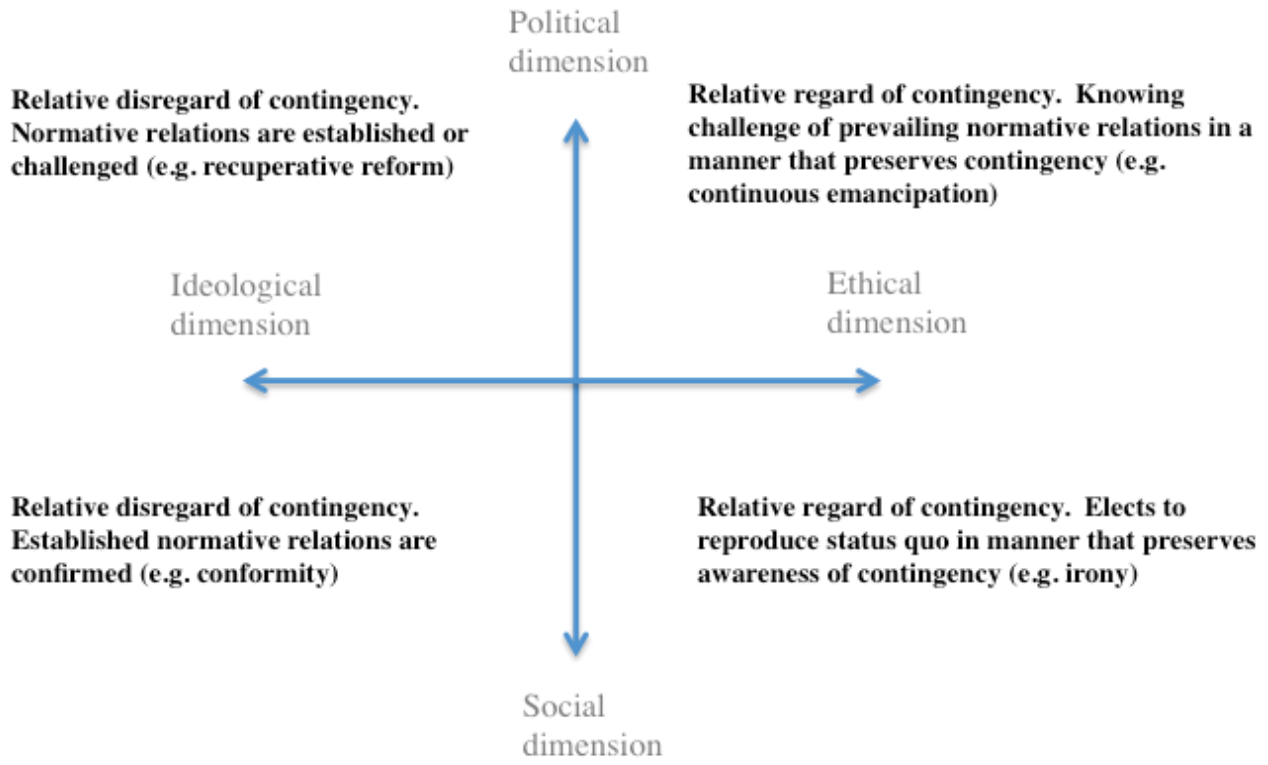

Key

Social dimension: "subjects are absorbed in their practices...the radical contingency of social relations has not been registered in the mode of public contestation"

Political dimension: "subjects articulate their feelings of dislocation by reactivating the contingent foundations of and challenging - existing social relations in the name of a principle or ideal"

Ideological dimension: "subjects are complicit in concealing the radical contingency of social relations"

Ethical dimension: "subjects engage in their practices in a way that is attentive to the radical contingency of social relations"

Figure 2: Four dimensions of social relations (Glynos and Howarth 2007:112), adapted to show empirical indicators of different configurations of Logics 